\title{
NEISSERIA GONORRHOEAE PRODUTORA DE PENICILINASE. PRIMEIRA CEPA ISOLADA EM SÃO PAULO, SP (BRASIL)
}

\author{
Clovis Lombardi* \\ Luiz Fernando de Góes Siqueira* \\ Manuel Fernando Queiroz dos Santos Júnior* \\ Waldemar Francisco** \\ Walter Belda*
}

LOMBARDI, C. et al. Neisseria gonorrhoeae produtora de peniçilinase. Primeira cepa iso lada em São Paulo, SP (Brasil). Rev. Saúde públ., S. Paulo, $19: 374-6,1985$.

RESUMO: Relata-se o primeiro caso identificado de Neisseria gonorrhoeae produtora de penicilinase (NGPP) no Estado de São Paulo, Brasil, demonstrando a necessidade de mensurar os índices de prevalência destas cepas na população.

UNITERMOS: Neisseria gonorrhoeae. Penicilinase.

\section{INTRODUÇAOO}

O surgimento de cepas de Neisseria gonorrhoeae produtoras de penicilinase (NGPP) vem se constituindo, nas últimas décadas e na maioria dos países ocidentais, em um dos componentes mais importantes da complexa epidemiologia das Doenças Sexualmente Transmissíveis (DST). A gonorréia é a mais freqüente das DST e a interrupção da sua cadeia de transmissão baseia-se fundamentalmente no diagnóstico e tratamento de casos clínicos. Neste contexto, o aparecimento de variantes bacteriológicas do microorganismo resistentes às terapêuticas disponiveis representa importante fator negativo para o controle da doença. Note-se que apesar do aparecimento recente de uma série de antibióticos eficazes no tratámento da gonorréia, a penicilina ainda representa, em termos de controle sanitário, o antibiótico de eleição, principalmente em países não desenvolvidos, devido à baixa toxicidade e ocorrência de efeitos colaterais, bem como seu baixo custo ${ }^{1,4}$.

A Neisseria gonorrhoeae pode apresentar fundamentalmente dois tipos de mecanismos de resistência, quer à penicilina quer a outros antimicrobianos. O primeiro deles, específico para a penicilina, é representado pela produção de uma enzima denominada $\beta$-lactamase (penicilinase), que desnatura o núcleo central da molécula do antibiótico (anel $\beta$-lactâmi$c o$ ), inativando-o. Este tipo de resistência pode ser transferido entre bactérias através da troca de plasmideos. O segundo mecanismo de resistência pode ser dirigido a outras drogas antimicrobianas, e é especificamente ligado à alteração de uma característica cromossômica da bactéria.

A distribuição geográfica da prevalência de cepas de NGPP mostra variações importantes, condicionantes da existência de verdadeiros bolsões de bactérias resistentes em algumas populações.

\footnotetext{
- Do Departamento de Epidemiologia da Faculdade de Saúde Publica da Universidade de São Paulo Av. Dr. Amaldo, $715-01255$ - São Paulo. SP - Brasil.

* Do Departamento de Microbiologia do Instituto de Ciências Biomédicas da Universidade de São Paulo - Av. Prof. Lineo Prestes, $1.374-05508$ - São Paulo, SP - Brasil.
} 
LOMBARDI, C. et al. Neisseria gonorrhoeae produtora de penicilinase. Primeira cepa isolada em São Paulo, SP (Brasil). Rev. Saúde públ., S. Paulo, 19:374-6, 1985.

No Brasil a situação é pouco conhecida, já tendo sido isoladas cepas resistentes em Recife (Pernambuco) ${ }^{3}$ e em Brasília (Distrito Federal)* com níveis de prevalência cujo padrão até o momento mostra-se inconclusivo.

A população da cidade de São Paulo, metrópole brasileira e centro de convergência nacional e internacional, possivelmente possui um "pool" de cepas de Neisseria gonorrhoeae de características cosmopolitas, o que torna de grande interesse o conhecimento dos índices de prevalência de NGPP em nosso meio.

Com este objetivo, o Departamento de Epidemiologia da Faculdade de Saúde Pública da Universidade de São Paulo (FSP/USP), área de Dermatologia Sanitária, está realizando, em colaboração com a Universidade Erasmus de Roterdam e o Instituto de Medicina Tropical de Antuérpia, um estudo de prevalência de cepas de NGPP entre pacientes atendidos no Serviço de Dermatologia Sanitária do Centro de Saúde "Geraldo Horácio de Paula Souza" da FSP/USP.

Esta nota diz respeito ao primeiro caso de identificação de Neisseria gonorrhoeae produtora de penicilinase no Estado de São Paulo, dentro deste programa.

CASO: D.F., 23 anos, masculino, preto, solteiro, residente em São Paulo.

Em 21 de maio de 1985, o paciente procurou o Serviço de Dermatologia Sa- nitária do Centro de Saúde "Geraldo Horácio de Paula Souza", com queixa de secreção uretral há dois dias, e possível tempo de incubação de dois dias.

$\mathrm{Na}$ bacterioscopia, pelo Gram, evidenciou-se mais de 100 leucócitos polimorfonucleares, por campo, e numerosos diplococos gram-negativos intra e extracelulares com características morfológicas do gênero Neisseria.

Inicialmente, o paciente foi tratado com 4.800.000 U.I. de penicilina G procaina I.M., associada a uma grama de probenecide por via oral.

Foi semeada amostra de secreção em meio de Thayer-Martin modificado (TMM). Em 24 h houve crescimento de colônias pequenas, transparentes, com características do gênero. A prova de oxidase foi positiva. Submetida as provas de acidificação de açúcares, verificou-se positividade apenas para glicose, caracterizando assim a Neisseria gonorrhoeae.

Após $48 \mathrm{~h}$ de tratamento o paciente apresentava o mesmo quadro clínico inicial.

O paciente recebeu então $5 \mathrm{~g}$. de Tianfenicol granulado, em dose única, e, $24 \mathrm{~h}$ após, a secreção desapareceu.

A partir da cepa isolada em cultura de TMM pesquisou-se a produção de $\beta$-lactamase pelo método da cefolosporina cromogênica ${ }^{2}$, sendo esta positiva.

\footnotetext{
* Informação comunicada no I Encontro Nacional sobre Doenças Sexualmente Transmissíveis e III Simpósio sobre Doenças Sexualmente Transmitidas no Brasil Central. Brasília, DF, 1984.
} 
LOMBARDI, C. et al. Neisseria gonorrhoeae produtora de penicilinase. Primeira cepa isolada em São Paulo, SP (Brasil). Rev. Saúde públ., S. Paulo, 19:374-6, 1985.

LOMBARDI, C. et al. Penicillinase producing Neisseria gonorrhoeae. The first strain isolated in S. Paulo, Brazil. Rev. Saúde públ., S. Paulo, 19:374-6, 1985.

ABSTRACT: This paper reports on the first case of penicillinase-producing Neisseria gonorrhoeae (PPNG) isolated in S. Paulo, Brazil, demonstrating the necessity of measuring the prevalence of these strains among the population.

UNITERMS: Neisseria gonorrhoeae. Penicillinase.

\section{REFERENCIAS BIBLIOGRÁFICAS}

1. HOLMES, K.K. \& BEATY, H. Infecções gonocócicas. In: Wintrobe, M.M. et al. Harrison's medicina interna. Rio de Janeiro, Guanabara Koogam, 1977. p. 727-30.

2. LENNETTE, E.H. Manual of microbiology clinical. 3rd ed. Washington,D.C., American Society Microbiology, 1980. cap. 46, p. 484.

3. MAGALHÃES, M. Uretrite causada por Neisseria gonorrhoeae produtora de penicilinase. Relato de um caso. Rev. bras. Pat. clin., 20:116-8, 1984.
4. WILLCOX, R.R. The management of sexually transmitted diseases: a guide for the general practitioner. Copenhagen, WHO. Regional Office for Europe, 1979. (OMS-EURO - Reports and Studies, 12).

Recebido para publicação em 05/06/1985

Aprovado para publicação em 28/06/1985 